\title{
Personal Protective Equipment-Related Nasal Bridge Folliculitis in a Corona Warrior
}

\author{
Rajeev Sharma ${ }^{1}$ Ashish Bindra ${ }^{2}$ Kapil Dev Soni ${ }^{3}$ \\ ${ }^{1}$ Department of Neurosurgery, All India Institute of Medical \\ Sciences, New Delhi, India \\ ${ }^{2}$ Department of Neuroanaesthesiology and Critical Care, Jai \\ Prakash Narayan Apex Trauma Center, All India Institute of Medical \\ Sciences, New Delhi, India \\ ${ }^{3}$ Department of Critical and Intensive Care, Jai Prakash Narayan \\ Apex Trauma Center, All India Institute of Medical Sciences, New \\ Delhi, India \\ Indian J Neurosurg 2022;11:67-69
}

\begin{abstract}
Address for correspondence Rajeev Sharma, MCh, Department of Neurosurgery, Room 713, Seventh Floor, Cardio Neuro Centre, All India Institute of Medical Sciences, New Delhi 110029, India (e-mail: rajufbd79@gmail.com).
\end{abstract}

\begin{abstract}
Nasal bridge is a common site suffering personal protective equipment-induced skin damages over face among first-line health care workers in this coronavirus disease

Keywords

- skin lesions 2019 pandemic. We hereby report folliculitis as a complication following regular use of N95 respirator and goggles, unreported in literature till now.

- COVID-19

- personal protective equipment
\end{abstract}

\section{Introduction}

This article highlights the personal experience of the first author.

In the wake of coronavirus disease 2019 (COVID-19) pandemic, All India Institute of Medical Sciences, New Delhi, has converted its Jai Prakash Narayan Apex Trauma Centre into a COVID hospital, where doctors of various specialties are taking care of corona-positive patients. We wear recommended personal protective equipment (PPE) and follow the donning and doffing procedures diligently ( - Fig. 1A). Besides, wearing masks in patient care areas, wearing mask is mandatory within the hospital premises and also during visits to community. It results in prolonged usage of mask in health care workers (HCWs). N95 respirator and goggles/face shields are indispensable components to be donned before going to the COVID areas to prevent viral spread by respiratory droplets. ${ }^{1}$ After donning, we stay for 4 to 5 hours per day in COVID area doing patient care. Pressure sores have been reported with prolonged usage of face masks in HCWs. ${ }^{2}$ We hereby report a complication following regular use of N95 respirator and goggles, unreported in literature till now.

\section{Case Summary}

As I was wearing N95 respirator and goggles over the last many days, I noticed minimal nasal bridge soreness after doffing one afternoon. As it was a very mild discomfort only on touching the nasal bridge, I assumed it would subside spontaneously over next few hours after removing N95 and goggles. Next day early morning around 4 AM, I woke up due to throbbing pain in my nose. When I inspected my face in the mirror, I noticed multiple tiny pustules with surrounding redness at the same site where I was feeling soreness the previous day (-Fig. 1B). My nasal bridge was tender to touch and surrounding skin was edematous and shiny. Blood sugar levels were normal. There was no active pus discharge or comorbidities; and constitutional symptoms were absent. I consulted my ENT colleague, who ruled out nasal involvement published online June 15, 2021
DOI https://doi.org/ $10.1055 / \mathrm{s}-0041-1722834$ ISSN 2277-954X.
(C) 2021. Neurological Surgeons' Society of India.

This is an open access article published by Thieme under the terms of the Creative Commons Attribution-NonDerivative-NonCommercial-License, permitting copying and reproduction so long as the original work is given appropriate credit. Contents may not be used for commercial purposes, or adapted, remixed, transformed or built upon. (https://creativecommons.org/licenses/by-nc-nd/4.0/).

Thieme Medical and Scientific Publishers Pvt. Ltd. A-12, 2nd Floor, Sector 2, Noida-201301 UP, India 

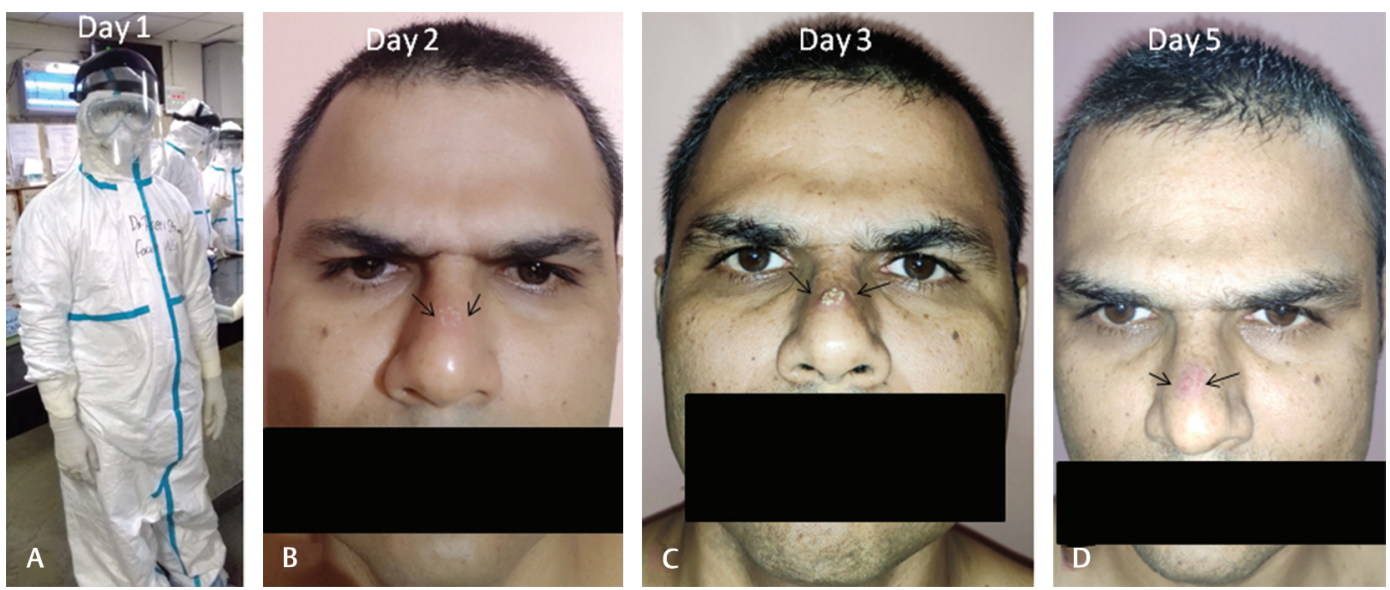

Fig. 1 Clinical photographs showing patient (A) donning personal protective equipment, (B) multiple tiny pustules over nasal bridge on day 2, (C) pustules became more prominent on day 3, (D) partial resolution of pustules and associated inflammation on day 5 (arrows).

as nasal cavity examination was normal. Dermatologist opinion was taken; diagnosis of superficial folliculitis was made and was managed successfully by oral amoxicillin therapy and povidone iodine application ( - Fig. 1C, D). It took 6 days to heal completely making me unavailable for COVID patient care for these 6 days. Wound swab (pus) culture and COVID testing were not done.

\section{Discussion}

The well-known phenomenon of skin lesions (like pressure ulcers) over bony prominences of the face (like dorsum of nose) with noninvasive ventilation face masks has recently been reported with N95 respirators in HCWs also. ${ }^{2}$ Nasal bridge $(83.1 \%$ ) has been reported as the most common site suffering skin damages by PPE among firstline HCWs in this COVID-19 pandemic. ${ }^{3}$ Risk of N95 masks and/or goggles-associated skin lesions in HCWs increases when they are worn for more than 6 consecutive hours. ${ }^{4}$ Pressure injury of skin overlying the bony prominences of the face usually starts with erythema of the intact skin. If adequate amount of pressure (higher than the capillary filling pressure of skin) is prolonged or pressure is combined with shear, it can lead to skin and soft tissue ischemia and necrosis, finally leading to ulcer formation. ${ }^{5}$ Damaged skin barrier adds an entry route for the novel coronavirus and other pathogens. ${ }^{4}$ In our case, pressure injury to skin was not prolonged enough to cause ulcer, but was sufficient enough to cause erythema which in combination with excessive sweating-associated blocking of hair follicles led to folliculitis. Folliculitis is defined as inflammation of the hair follicle either due to infection, chemical irritation, physical injury, or occlusion. Staphylococcus aureus is a common pathogen of bacterial folliculitis and managed by antibiotic therapy. ${ }^{6}$

Prolonged use of a very snugly fitted or inappropriate fitted (causing shear) N95 respirator, pressure application using plaster for securing it tightly and to prevent fogging of goggles, accompanied by pressure, and abrasive effect of overlying goggles with excessive sweating due to PPE

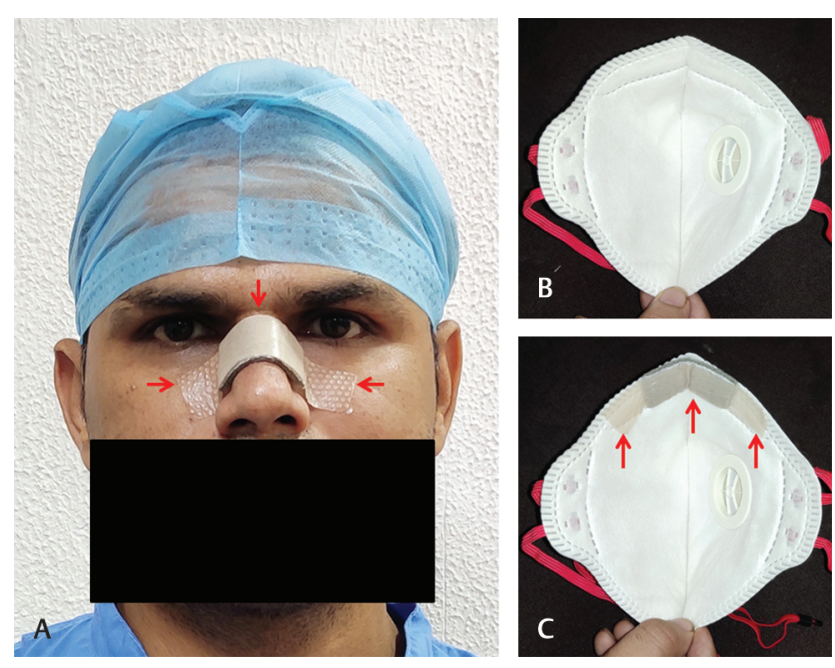

Fig. 2 Clinical photographs showing patient (A) sticking absorbent foam dressing over nasal bridge (marked by red arrows) to reduce overlying pressure of facemask and goggles, (B, C) before and after sticking absorbent foam dressing on inner surface of nose piece of N95 respectively (marked by red arrows).

are the likely factors responsible for such complications, which can be prevented by its intermittent use, application of pressure-reducing dermal gel pads, skin-friendly protective/barrier dressings like hydrocolloid dressings, or barrier creams (apply half an hour before donning) over bony prominences. ${ }^{2-4}$ Before donning N95, sticking a strip of absorbent foam dressing over nasal bridge ( - Fig. $2 \mathbf{2 A}$ ) or padding the nose piece of N95 ( - Fig. 2B) by sticking the absorbent foam dressing on its inner surface ( - Fig. 2C) can be the other protective options. People with thin skin, poor hydration, and on steroid therapy are at a higher risk of such complications than others and thus need these prophylactic measures more often than others. ${ }^{7}$ Also, protective devices made of soft malleable material only should be procured by hospitals to avoid such complications, as HCW developing such complication will be unfit for work in COVID areas leading to acute scarcity of human resources for COVID patient care. ${ }^{7}$ 
Any pain or erythema at the site of N95 respirator or goggle application should also be followed diligently.

\section{Conflict of Interest}

None declared.

\section{References}

1 Garcia Godoy LR, Jones AE, Anderson TN, et al. Facial protection for healthcare workers during pandemics: a scoping review. BMJ Glob Health 2020;5(5):e002553

2 Lam UN, Md Mydin Siddik NSF, Mohd Yussof SJ, Ibrahim S. N95 respirator associated pressure ulcer amongst COVID-19 health care workers. Int Wound J . 2020;17(5):1525-1527
3 Lan J, Song Z, Miao X, et al. Skin damage among health care workers managing coronavirus disease-2019. J Am Acad Dermatol 2020;82(5):1215-1216

4 Sernicola A, Chello C, Cerbelli E, et al. Treatment of nasal bridge ulceration related to protective measures for the COVID-19 epidemic. Int Wound J. 2020;17(5):1520-1522

5 Thompson D. A critical review of the literature on pressure ulcer aetiology. J Wound Care 2005;14(2):87-90

6 Sun KL, Chang JM. Special types of folliculitis which should be differentiated from acne. Dermatoendocrinol 2017;9(1):e1356519

7 Rathore FA, Ahmad F, Zahoor MU. Case report of a pressure ulcer occurring over the nasal bridge due to a non-invasive ventilation facial mask. Cureus 2016;8(10):e813 